\section{B A Institute of \\ YK Business Administration \\ 六下 \\ Karachi \\ Leadership and Ideas for Tomorrow}

Business Review

Volume 3 Issue 2 July-December 2008

$7-1-2008$

\title{
The influence of culture on advertising effectiveness in Pakistan and Australia: A cross-cultural study
}

Faiz Muhammad Shaikh

Z.A Bhutto Agricultural College, Dokri, Pakistan

Follow this and additional works at: https://ir.iba.edu.pk/businessreview

Part of the Advertising and Promotion Management Commons

cc) (7)

This work is licensed under a Creative Commons Attribution 4.0 International License.

\section{Recommended Citation}

Shaikh, F. M. (2008). The influence of culture on advertising effectiveness in Pakistan and Australia: A cross-cultural study. Business Review, 3(2), 1-18. Retrieved from https://doi.org/10.54784/ 1990-6587.1156

This article is brought to you by iRepository for open access under the Creative Commons Attribution 4.0 License and is available at https://ir.iba.edu.pk/businessreview/vol3/iss2/10. For more information, please contact irepository@iba.edu.pk. 


\title{
DISCUSSION
}

\section{The Influence of Culture on Advertising Effectiveness in Pakistan and Australia: A Cross-Cultural Study}

\author{
Faiz Muhammad Shaikh \\ Z.A Bhutto Agricultural College -Dokri, Pakistan
}

\begin{abstract}
$\mathrm{P}$ resents findings from an empirical study, which investigates the effects of different advertising appeals used across cultures. Cultural differences along the individualism collectivism dimension are hypothesized to affect people's reactions to certain advertising appeals. Results indicate that appeals, which emphasize individualistic benefits, are more effective in the Australia than in Pakistan. When appeals emphasizing collectivistic benefits are employed, they are generally more effective in Pakistan. However, such effects can be moderated by product characteristics. Different product types may serve to influence the effectiveness of culturally congruent advertising appeals. Discusses the implications of the findings, that cultural differences play a significance role in advertising. This paper proposes that ads, which activate identification with one's gender group, will have a more favorable impact on future brand and ad judgments than ads that do not activate this identity. The foundation for this proposed influence is based on social identity theory, ad processing, and gender research.
\end{abstract}

Keywords: Advertising, Australia, National Culture, Pakistan.

\section{INTRODUCTION}

Advertising is typically thought of as one of many external influences on, culture, family, reference groups, and social and situational influences. This research focuses on the how crosses cultural segments play a role for perceiving different ads of Pakistani customers compare to Australia. Additionally, as consumers become bombarded with more and more advertisements, many claim that ads have little or no influence on their judgments or actions (Bearden, Netemeyer and Teel 1989). In spite of these criticisms, advertising is considered an efficient way of reaching many consumers. Therefore, marketers continue to seek ways to increase the influence of advertising on their audience. For instance, an ad could be linked to another source of external influence such as one's culture (Sirgy 1982). While most external influences have been well studied, the potentially powerful influence of gender group identity has received little attention. The question becomes how can the activation of a gender group identity result in favorable ad and brand judgments? 
This paper provides a theoretical foundation and conceptual model explaining how ads may influence attitudes and purchase intentions by activating an identity with one's gender group (Turner et al. 1994, p. 458).

The model in Figure 1 depicts the process by which ads may activate a gender group identity and thereby influence ad and brand judgments. The discussion of the first box in the model addresses the question: Can an ad activate a gender group identity? A gender group identity is an example of a social identity in which one sees oneself as a member of the gender group. It is possible that such an identity could be activated through exposure to ads that pair a brand with members of one's gender group(Kolbe and Langefeld 1991). The activation of a gender group identity is thought to result in that identity gaining salience over other existing identities. Given that individuals hold many social identities simultaneously, it is necessary that the context (ads) bring the desired social identity to the forefront. In other words, the ads must make a gender identity salient in order to have the desired effect. The second box focuses on the issue of salience and the internal consequences of a salient gender group identity. The third box indicates that salience may be influenced by how strongly one identifies with one's gender group. Finally, the discussion of the fourth box addresses the question of whether or not the internal consequences of a salient gender identity can influence ad and brand judgments. This paper proposes that ads, which activate identification with one's gender group, will have a more favorable impact on future brand and ad judgments than ads that do not activate this identity. The foundation for this proposed influence is based on social identity theory, ad processing, and gender research.

\section{GENDER GROUP IDENTITY ACTIVATING ADS}

We begin our discussion of the dynamics involved in using gender group identity to influence ad and brand judgments by providing a theoretical underpinning for the notion that ads can prime identification with a gender group and cause that identity to become salient.

This requires an understanding of the concept of gender identity from a social identity perspective. A social identity approach to understanding gender influence on advertising results is also consistent with marketing literature on ad processing. Marketing literature identifies categorization, elaboration, and congruency as three important concepts in ad processing. Categorization theory holds that individuals automatically attempt to match new stimuli with an evoked category description. If a gender group identity is activated by an ad, then the product depicted in the ad may become linked to the gender category thereby triggering the use of category attributes in evaluating the product. Elaboration is thought to facilitate the categorization of stimuli. Gender group activating ads would require an advanced type of elaboration known as semantic analysis. A semantic analysis requires the 
spreading of an activated concept to other related concepts held in memory. It is anticipated that the expectancies generated by the gender group depicted in the ad would be used to create expectancies about the products depicted in the ad. A key factor in this process, however, is congruency. Congruency refers to the match between the stimulus and the category prototype or exemplar. The closer the fit between the gender depicted in the ad and the prototype a person holds of his/her gender, the more likely that the appropriate gender schema will be activated and the more likely it is that those schema evaluations will be used to evaluate the targeted product.

\section{GENDER GROUP IDENTITY SALIENCE AND STRENGTH}

We propose in this paper that ads which contain depictions of the gender group will prime gender salience. In social identity theory, salience is the psychological significance of the social category. In other words, it refers to the identity that is functioning psychologically to increase the influence of group membership on behavior. Salience is believed to be the result of accessibility and fit. Accessibility is the readiness of an individual to use a particular self-category, and fit is the degree to which the stimuli in the given context actually match the criteria which define the category. Gender is believed to rate high on both accessibility and fit. A strong identification with one's gender group may further enhance the accessibility of a gender group identity.

\section{AD AND BRAND JUDGMENTS}

Social identity provides a fresh approach to understanding the influence of gender identity on ad processing. Identifying with a social group such as one's gender group has been shown to create an in-group bias favoring the norms and prototypes of the group, leading to attitudinal and behavior conformity. This paper proposes that these favorable outcomes may be carried over to associated ad and brand judgments. Employing the use of social identity activation in ads may increase the value of advertising dollars.

\section{SOCIAL IDENTIFICATION AND CULTURE}

Consumer behavior studies have a strong history of looking at individual characteristics and their influence on behavior. For example, in Australia, selfconcept has been conceptualized as a personal identity (Sirgy 1982), reference group influence measured as susceptibility to interpersonal influence (Bearden, Netemeyer and Teel 1989), and identification with a group produces behavior that is representative of the norms of that group. Behavior then, is influenced not only by how you see yourself as an individual, but also by seeing yourself gendered situations and cognitive images to opt for gendered strategies. 
The cultural rules and cognitive images that give shape and substance to our daily lives are profoundly attached to our biological sex and may be inescapable.

Social identity theory incorporates many of the aspects of the integrated tradition supported by Risman. Gender is one example of a social category (or group). Social identity theory recognizes that our concepts of social categories such as gender are developed in a social context that influences the values and meanings associated with that membership group. Members of that social group internalize these values and meanings. The members identify with the gender group, see themselves as representative of that group and model their behavior accordingly. This paper proposes that a gender identity can be activated by an advertisement. Since identification is believed to influence attitudes and behavior, it is proposed that ads that activate identification with one's gender group will result in a more favorable impact on future brand and ad judgments than ads that do not activate this identity. In congruence with Risman's interact ional tradition described above, social identity theorists view self-concept as an expression of a dynamic process of social judgment rather than a relatively fixed mental structure as would be depicted by the individualistic tradition. Self-concept is seen as a "flexible, constructive process of judgment and meaningful inference in which varying self-categories are created to fit the perceiver's relationship to social reality. The emerging and varying self-concepts represent the individual in terms of his or her changing social contextual properties" (Turner et al. 1994, p. 458). Membership in large-scale social categories are that the individuals concerned define themselves and are defined by others as members of a group. The groups do not depend on size, the frequency of inter-member interaction, physical contact, systems of role relationships, or interdependent goals. Apparently, what a matter is how people perceive and define themselves and not how they feel about others or how others feel about them. Social or group categorization not only locates a person's identity within a categorical hierarchy, it also brings with it a sense of what it means to belong to that social grouping. For example, the "female" category brings with it issues of gender, or what it means to be female in a particular culture. According to Deaux (1992), social identity without the meanings that individuals use to fill these categories remains an empty container. Bem's Gender Schema Theory offers us some insights into these meanings in a gender category. This theory deals with sex typing, which is the process by which a society metamorphoses male and female into masculine and feminine (Bem 1981). A gender schema is a cognitive structure of what it means to be male and female. According to Bem's Gender Schema Theory, from early in life, individuals categorize people, objects, and behaviors as masculine or feminine, and usually have pre-set notions as to what is appropriate for each gender (Kolbe and Langefeld 1991). The sex-role stereotypes become internalized to varying degrees among individuals in a society and new or incoming information is processed in relation to the existing schemas. Appropriate gender stereotypes are learned from a variety of sources, including 
advertising. However, some researchers note that much of advertising contains idealized images and can create unattainable or aspirational perceptions of gender expectations that can have a negative impact on self image (Martin and Gentry 1997; Martin, Gentry and Hill 1999; Richins 1991). This appears to be especially detrimental for pre-adolescent and adolescent females. Individuals concerned about sex typing regulate their behavior so that it conforms to the culture's definitions of gender appropriateness (Schmitt, Leclerc and Dubé-Rioux 1988). West and Zimmerman (1987) point out that we expect and want to know the sex category of those around us and we presume that others are displaying it for us, in as decisive a fashion as they can so that we can act accordingly. In their words, gender is something "we do" in order to make life more manageable. Although Schmitt, Leclerc, and Dubé-Rioux did not find the support they expected for gender schema theory, as we will see later in this paper, the salience of one's gender (a situational characteristic) may have a stronger influence on behavior than whether or not one is a sex-typed individual (a personality characteristic).

\section{AD CONTENT}

Ads designed according to the first box of the model in Figure 1 must convey or bring to mind membership in one's gender group and this sort of ad is accepted in Australian Culture but Pakistani culture they won't accepted this sort of ad.. This is accomplished through context, contrast of social groups, and identification.

\section{PAKISTANI AD}

In above ads they are acceptable in the Australian culture but in our culture these ads are not acceptable because we have different culture and environment. ContextOne's self-concept consists of numerous concurrent social group or category identities. Across time and different situations, different identities come to the forefront. Social identity, then, is situational or contextually based. "Different situations tend to 'switch on' different conceptions of self so that social stimuli are construed and social behavior controlled in the appropriately adaptive manner" (Turner 1982, p. 20). Turner (1994) further argued that self-categorizing is inherently variable, fluid, and context dependent, inasmuch as self-categories are socially comparative and are always relative to a frame of reference. Similarly, shifts in social identification are totally dependent on context, a result of the particular distribution of people and attributes in the environment (Deaux 1996). It follows then, that group memberships have a variable impact on our working self-concept, and whether we categorize ourselves (and others) as group members, and which groups we categorize ourselves (and other people) into and the resulting behavior depends to a large extent on the social context (Simon, Hastedt and Aufderheide 1997). The ads in the first box of the model provide this context by depicting targeted brands and members of the gender group. 
Contrast- One critical aspect of the context is the relevant "other." Social identities or self-categorizations are established in contrast to some other class of stimuli. Thus, the identification process involves not only recognition of one's membership in a group, but a contrast of the individual's own group with another group (Deaux 1992; Turner 1987). The comparison group is not just any out-group, but one that differs on dimensions.

Clear physical differences between groups help maintain the separateness and clarity of the categorizations, but only if the differences are relevant, relational attributes that have evaluative significance (Tajfel and Turner 1986; Turner 1987). Gender is a viable social group for the proposed study as for the most part it contains two distinct groups that are easily recognized and compared.

Identification- Identification with a social category is another important factor in social group influence on behavior. There is a difference between personal and social or shared identity. Personal identity refers to self-categories that define a person as a unique individual in terms of his or her individual differences from other in-group persons. Social identity refers to self-categories that define the individual in terms of his or her shared similarities with members of certain social categories in contrast to the differences of other social categories (Deaux 1996; Turner et al. 1994). In other words, a personal identity refers to how people view themselves as individuals whereas social identity refers to how they view the social groups to which they belong (Luhtanen and Crocker 1992) and their membership in that group. Social identity, then, embraces a shift towards the perception of oneself as an interchangeable exemplar of a social category and away from the perception of self as a unique person (Brewer 1991; Turner 1987). Identification begins with the application of a label to oneself (Deaux 1996). It is not enough that other people place a person in a particular group. The individual must accept and acknowledge the categorization (Brewer 1991). It is particularly important to note that some social identities are based upon categories with distinguishing physical features such as age, race, and gender, making it tempting for the researcher to impose categorization. Despite agreement by researchers that the category is appropriate, the person may not choose to endorse that identification for the self (Deaux 1996). There may also be instances where one person may be simultaneous members of more than one demographic group such as a person of mixed ethnic heritage, or the rare instance where an individual may be of mixed sex (for a discussion of five possible sexes, see Fausto-Sterling 2002). To accommodate this need for self-identification, subjects in studies dealing with gender group identity, for example, should be asked to identify the gender group with which they mostly closely identify, the gender group associated with males or the gender group associated with females. While there may be a rare case where an individual finds a need for more than the two gender categories, as Fausto-Sterling points out, in today's society, most hermaphrodites and 
pseudohermaphrodites are surgically treated at birth to align with one or the other sex, and the child raised as either a male or a female. Regardless of the social label selected, the critical point is that the subject must accept and acknowledge the categorization and apply the label to him self or herself.

\section{AD PROCESSING}

Marketing literature identifies categorization, elaboration, and congruency as three important concepts in ad processing. Categorization theory holds that people naturally divide their world into categories that enable them to efficiently understand and process information in the environment (Sujan 1985). When a new stimulus is encountered, the perceiver automatically attempts to match it with an evoked category description. The evoked category attributes, links and exemplars are then used to aid in the evaluation of the new stimulus (Goodstein 1993). A gender group identity can be an example of such a category. It may be that if a gender identity (a social category) is activated, then the product depicted in the ad may become linked to the category, thereby triggering the use of category attributes, etc. in the evaluation of the product. In this case, the perceiver would be responding to the category level rather than on the basis of the individual attributes of the product (see Sujan 1985). According to Putrevu's review of ad processing differences between men and women, females may be especially adept at processing ads that appeal to a category level rather than individual product attributes (Putrevu 2001).

Previous studies suggest that people can employ two types of elaboration (see Meyers-Levy 1991). The first and most basic is item-specific or feature analysis (Meyers-Levy and Malaviya 1999). Greenwald and Leavitt (1984) refer to this type of analysis in the pre attention stage of their four-level model of involvement. In this stage, they describe the pre attentive analysis as involving a sensory perusal of visual or auditory inputs. According to Shapiro (1999, p. 16), "a feature analysis implies that the memory trace produced at exposure only contains information regarding the perceptual features of the ad content (e.g., contours, brightness, contrasts) and not its meaning." MacInnis and Jaworski (1989) proposed that a feature analysis is only the first of six levels of mental processing. The remaining five levels of mental processing (basic categorization, meaning analysis, information integration, roletaking and constructive processes) relate more to the second level of elaboration, which is a relational or semantic analysis.

This more advanced type of elaboration cultivates the processing of information associated with the categories to which an object might belong (Malaviya, Kisielius and Sternthal 1996). A semantic analysis requires the spreading of an activated concept to other related concepts such as when a stimulus sparks the activation of a particular node (or schema) which automatically leads to the activation of another, somehow, related node. It is like following the connections on a spider web. The 
memory trace then includes the activation of related schemas and the associated meanings (Shapiro 1999).

Placing the target product within a related contextual scene encourages relational or semantic analysis (Malaviya, Kisielius and Sternthal 1996). Context, in this instance, concerns the visual material surrounding the product within the confines of an ad (as opposed to visual material surrounding the ad itself such as other ads or articles). It appears that the contextual scene information activates a schema for the theme or gist of an ad prior to product identification. The activated schema in turn creates expectancies about the items depicted in the ad (Shapiro 1999). For example, the scene might spark an assessment of different categories of people who might use the product, objects related to its use, or occasions when it might be used (Malaviya, Kisielius and Sternthal 1996).

Prior studies indicate that women may be more apt to engage in elaboration than men. Apparently, men and women differ in their use of message cues and judgments (Meyers- One of the key factors in elaboration and categorization is congruency. In categorization theory, congruency refers to the match between the stimulus and the category prototype or exemplar. The closer the fit, the more likely that the schema will be activated and the more likely it is that schema evaluations will be used to evaluate the targeted product rather than product attributes (Goodstein 1993; Meyers-Levy and Tybout 1989; Sujan 1985). Shapiro's study (1999) indicates that a match between the product and the ad context facilitates semantic analysis. Loken and Ward (1990) cite studies which indicate that a strong match between the product and the category enhances free recall and increases the speed and accuracy of classification.

In social identity theory, context, contrast, and identity strength are all tied together in salience. Salience is the activation of a relevant self category. It is the psychological significance of the social category rather than its perceptual prominence. "By a salient group membership we refer to one which is functioning psychologically to increase the influence of one's membership in that group on perception and behavior... The term salience is not being used to refer to some 'attention-grabbing' property of a stimulus" (Turner 1987, p. 118). Salience is believed to be the result of accessibility and fit. Accessibility is the readiness of a perceiver to use a particular self-category, and fit is the degree to which the stimuli in the given context actually match the criteria which define the category (Turner 1987; Turner et al. 1994).

Again, gender should provide a strong study environment, as there would tend to be strong similarities within a gender group and sharp contrasts between gender groups.

Normative fit refers to how well the content of the stimuli group matches the categorical content. In other words, a group must not only differ from the out-group, it must differ in the expected ways. The similarities within the group and the 
differences between the groups must be consistent with one's normative beliefs and theories about the substantive social meaning of the social category (Turner et al. 1994). The activation of a gender identity in an ad would require a normative fit between the pictures of the gender group and brands that are expected to be used by members of that group. Overall, salience (or self-categorizing) always reflects an interaction both between comparative and normative fit and between fit and accessibility (Turner et al. 1994).

Since individuals hold many social identities simultaneously, it is necessary that the context (ads) bring the desired social identity (in this case gender) to the forefront. Social identity theory posits that even though we all hold multiple identities, the situational context can induce one of the identities to take temporary precedence over the other identities, and thereby have a stronger influence on behavior in that situation. In this situation, the ads must make a gender identity salient in order to have the desired effect. Previous work has shown that advertisements can make a social identity such as gender salient. Grier and Deshpandé (2001), for example, found that their ad primed a gender identity. Activation would be accomplished by pairing pictures of members of the gender group with brands whose use is consistent with the group's norms. Identifying appropriate brands would be accomplished by researching databases such as Simmon's Study of Media and Market, which identify brand usage by demographic groups. Subjects in the experimental group would view ads that paired brands with members of the matching gender group (gender identity activating ads). While it should be acknowledged that a number of execution cues such as models, music, shapes, and even color, might elicit a gender identity, it is likely that a group spokesperson/model is apt to be the most powerful element and most likely to generate an immediate identity activation. Since we all hold multiple identities simultaneously, it is important that the ads be pretested to ensure that the ads activate and make salient a gender identity. Subjects in the control group would see ads that only showed the brands. These ads would also have to be pretested to make sure that the brand only ads did not make the gender identity salient.

\section{STRENGTH OF GENDER IDENTITY}

Although self-identifying and defining oneself in terms of a group are thought to be indicative of high levels of group identification (Terry and Hogg 1996), several measures have been developed to gauge an individual's strength of identification with a group (e.g., Biernat, Green and Vescio 1996; Ethier and Deaux 1994; Terry and Hogg 1996). The lower box in the model depicted in Figure 1 is the strength of the social identity. How strongly one identifies with one's gender group is expected to impact salience. As stated in the following proposition, a strong identification with one's gender group should increase the likelihood of gender salience: 
A gender identity should be highly salient in women. As discussed earlier, social identity salience is believed to be the result of accessibility and fit. Gender rates high on both accounts. A gender identity is thought to be highly accessible (Deaux 1992) because it is a central part of one's self-definition. It is an identity with which the individual has a great deal of past experience, it has a high emotional and value significance and, along with age and race, it represents a higher hierarchical level. Gender also rates high on contextual fit. One of the key elements of contextual fit is comparative aspects between groups (Turner 1987). The greater the distinctions are between groups, the more likely one is to identify with one's social group rather than the out-group. The differences between men and women in our society are taught to us from birth. According to Risman (1998), gender structure can be conceived as both cultural rules and cognitive images, as tacit knowledge or expectations attached to a sex category. Such images are experienced as social facts whether or not the actors deviate from them, as they exist autonomously of their internalization as personality. Thus, gender is conceived as an emergent feature of social situations rather than the property of individuals, both as an outcome of and a rationale for various social arrangements.

\section{ADVERTISING AND BRAND JUDGMENTS}

The effects of a salient social identity can be seen in conformity to group norms, and an in-group bias. Social identity theory depicts a fairly direct relationship between self-categorization as a group member and normative in-group attitudes and behavior based upon the social group's prototype and norms (Abrams 1994; Biernat, Green and Vescio 1996). A group's prototype describes and prescribes beliefs, attitudes, feelings, and behaviors that optimally minimize in-group differences and maximize inter-group differences (Terry and Hogg 1996). Social identity proposes that group members are evaluated positively to the extent that they are perceived as prototypical of the self-category to which they are compared (Deaux 1996). Similarly, a person who identifies with a group will be more attracted to members who typify group attributes.

In other words, consumers who identify with a particular social group would tend to think, feel, and behave in terms of the group norms. This may have an influence on how they evaluate products and brands as well as on what they buy, and how they use what they purchase. Just as groups are closely tied to social categories, norms are closely tied to the prototype.

The prototype includes a representation of accepted norms of a social category or group. Norms are the accepted or implied rules that specify how group members should behave (Terry and Hogg 1996). They are an emergent property of group formation (Turner 1987) and represent the group's socially desirable and expected attitudes and behaviors that group members will strive to enact (Turner 1982). 
Norms are said to "prescribe the context-specific attitudes and behaviors appropriate for group members" (Terry and Hogg 1996, p. 780). Norms are seen as part of the social identity process leading from categorical inclusion to expected behavior. According to Turner (1982), individuals first define themselves as members of a distinct social category. They then form or learn the stereotypical norms of that category. They discern that certain ways of behaving are correlated attributes of category membership and that certain appropriate, expected, or desirable behaviors are used to define the category as different from other categories. They then assign these norms to themselves along with other stereotypical attributes of the category, making their behavior become more normative as their category membership becomes salient. It is assumed that people define themselves in terms of their social group memberships and they enact roles as part of their acceptance of the normative expectations of in-group members. The norms become privately accepted and are both privately and publicly enacted, resulting in conformity (Abrams 1994; Turner et al. 1994).

In-group bias is represented by a favorable evaluation and attitude toward in-group members. Studies have shown that the mere perception of belonging to a group is sufficient to trigger inter-group discrimination favoring the in-group (Tajfel and Turner 1986). The resulting intra-group cohesion may be evidenced by more positive attitudes towards and more reported liking of in-group than out-group members, ethnocentric biases in perception, evaluation and memory and an altruistic orientation towards in-group members (Turner 1988).

\section{CONCLUSION}

This research abased on the ads and their impact on different cultures the case of cross-cultural influences of Australia and Pakistan. The social identification tends to lead to the perceived similarity of members, mutual attraction between members or social cohesion, mutual esteem, emotional empathy, altruism and cooperation, and attitudinal and behavioral uniformity. Therefore, according to social identity theory, a salient social identity should result in outcomes consistent with and favorable toward the activated social identity. Therefore, it is proposed model, the outcome is favorable ad and brand judgments, and is represented in the last box in the model. Favorable ad and brand judgments could include such outcomes as brand inclusion in a consideration set, likelihood of purchase, attitude toward the ad and attitude toward the brand. The activation of a gender identity includes the identification of the prototype. This prototype would include both the members of the social category and group norms. The group norms would dictate that using the depicted brand was a normal or expected part of group members' behavior. One's gender identity is believed to be a very central (well learned and rehearsed) part of one's self-schema. 
Identities such as gender, for example, are thought to be very accessible, salient in more situations, and therefore more likely to influence behavior. This should facilitate the schema activations inherent in semantic elaboration and therefore increase the likelihood that the brand would be included in a consideration set. .

It is possible that identification with one's gender group could result in a less than favorable judgment or negative impact. For example, a negative portrayal of femininity could activate a gender group identity but result in a negative brand judgment. However, advertisers are likely to prevent this by pre testing ads for a favorable response before placing the ad. Some might also argue that, for example, a woman might not view the gender identity manipulation positively, perhaps viewing the presentation as too traditional for a feminist. In this case, a female gender identity may not be activated, but Rather, a subset of that gender identification.

\section{CONTRIBUTIONS AND DIRECTIONS FOR FURTHER RESEARCH}

This conceptual paper has provided an alternative view of influence of cultural norms values of advertising in cross cultural context, that is based upon defining oneself as a how perception regarding ads. Identifying with such a group has been shown to create an in-group bias favoring the norms and prototypes of the group, leading to attitudinal and behavioral conformity. This paper proposes that these favorable outcomes may be carried over to associated ad and brand judgments in Australian culture and Pakistani culture.

\section{REFERENCES}

Abrams, Dominic. 1992. "Processes of Social Identification." in Social Psychology of Identity and the Self Concept, ed. Glynis M. Breakwell. London: Surrey University Press, pp 57-99.

Bearden, William O., Richard G. Netemeyer and Jesse E. Teel. 1989. "Measurement of Consumer Susceptibility to Interpersonal Influence." Journal of Consumer Research 15 (March): pp 473-481.

Biernat, Monica, Michelle L. Green and Theresa K. Vescio. 1996. "Selective SelfStereotyping." Journal of Personality and Social Psychology 71 (6): pp 1194-1209.

Brewer, Marilynn B. 1991. "The Social Self: On Being the Same and Different at the Same Time.” Personality and Social Psychology Bulletin 17 (5): pp 475-482. 
Deaux, Kay. 1992. "Personalizing Identity and Socializing Self." in Social Psychology of Identity and the Self-Concept, ed. Glynis M. Breakwell. San Diego, CA: Surrey University Press.

Deaux, Kay. 1996. "Social Identification." in Social Psychology: Handbook of Basic Principles, eds. E. Tory Higgins and Arie W. Kruglanski. New York: Guilford Press, pp 777-798.

Deaux, Kay, Anne Reid, Kim Mizrahi and Kathleen A. Ethier. 1995. "Parameters of Social Identity.” Journal of Personality and Social Psychology 68 (2): pp 280-291.

Ethier, Kathleen A. and Kay Deaux. 1994. "Negotiating Social Identity When Contexts

Change: Maintaining Identification and Responding to Threat." Journal of Personality and Social Psychology 67 (2): pp 243-251.

Fausto-Sterling, Anne. 2002. "The Five Sexes: Why Male and Female are not Enough. in Sexuality and Gender, eds. Christine L. Williams and ARlene Stein. Malden, MA Blackwell Publishers, pp 468-473.

Fazio, Russel H. 1993. "Variability in the Likelihood of Automatic Attitude Activation: Data Reanalysis and Commentary on Bargh, Chaiken, Govender, and Pratto (1992).” Journal of Personality and Social Psychology 64 (5): pp 753-758.

Fazio, Russell H. and Bridget C. Dunton. 1997. "Categorization by Race: The Impact of Automatic and Controlled Components of Racial Prejudice." Journal of Experimental Social Psychology 33: pp 451-470.

Fazio, Russell H., Martha C. Powell and Carol J. Williams. 1989. "The Role of Attitude Accessibility in the Attitude-to-Behavior Process." Journal of Consumer Research 16(December): pp 280-288.

Goodstein, Ronald C. 1993. "Category-based Applications and Extensions in Advertising: Motivating More Extensive Ad Processing." Journal of Consumer Research 20 (June): pp 87-99

Greenwald, Anthony G. and Clark Leavitt. 1984. "Audience Involvement in Advertising: Four Levels.” Journal of Consumer Research 11 (June): pp 581-592.

Grier, Sonya A. and Rohit Desphandé. 2001. "Social Dimensions of Consumer Distinctiveness: The Influence of Social Status on Group Identity and Advertising 1 '8.Persuasion." Journal of Marketing Research 38 (May): pp 216-224. 
Haslam, S. Alexander, Penelope J. Oakes, Katherine J. Reynolds and John C. Turner. 1999. "Social Identity Salience and the Emergence of Stereotype Consensus." Personality and Social Psychology Bulletin 25 (7): pp 809-818.

Heckler, Susan E. and Terry L. Childers. 1992. "The Role of Expectancy and Relevancy in Memory for Verbal and Visual Information: What is Incongruency?" Journal of Consumer Research 18 (March): pp 475-492.

Hogg, Michael A. and Deborah Terry. 2000. "Social Identity and Self-Categorization Processes in Organizational Contexts." Academy of Management Review 25 (1): pp 121-140.

Janiszewski, Chris. 1988. "Preconscious Processing Effects: The Independence of Attitude Formation and Conscious Thought." Journal of Consumer Research 15 (September): pp 199-209.

Janiszewski, Chris. 1990. "The Influence of Print Advertisement Organization on Affect Toward a Brand Name.” Journal of Consumer Research 17 (June): pp 53-65.

Kolbe, Richard H. and Carl D. Langefeld. 1991. "Female Roles in Television Advertising: Viewers' Use of Gender Role Cues in Appraising Stereotypic and NonStereotypic Role Portrayals." in Gender and Consumer Behavior ed. Janeen Arnold Costa, Salt Lake City, Utah: Salt Lake City Utah: University of Utah Printing Service,

Lee, Yih Hwai and Charlotte Mason. 1999. "Responses to Information Incongruency in Advertising: The Role of Expectancy, Relevancy, and Humor." Journal of Consumer Research 26 (September): pp 156-169.

Loken, Barbara and James Ward. 1990. "Alternative Approaches to Understanding the Determinants of Typicality." Journal of Consumer Research 17 (September): pp $111-126$.

Luhtanen, Riia and Jennifer Crocker. 1992. "A Collective Self-Esteem Scale: Self Evaluation of One's Social Identity." Personality and Social Psychology Bulletin 18 (3): pp 302-318.

MacInnis, Deborah J. and Bernard J. Jaworski. 1989. "Information Processing from Advertisements: Toward an Integrative Framework." Journal of Marketing 53 (October):pp 1-23.

Malaviya, Prashant, Jolita Kisielius and Brian Sternthal. 1996. "The Effect of Type of Elaboration on Advertisement Processing and Judgment." Journal of Marketing Research 33 (November): pp 410-421. 
Maldonado, Rachel L. 2001. "The Effects of Social Identification in the Context of Incidental Ad Exposure." Dissertation. Washington State University.

Martin, Mary C. and James W. Gentry. 1997. "Stuck in the Model Trap: The Effects of Beautiful Models in Ads on Female Pre-Adolescents and Adolescents." Journal of Advertising 26 (2): pp 19-33.

Martin, Mary C., James W. Gentry and Ronald Paul Hill. 1999. "The Beauty Myth and the Persuasiveness of Advertising: A Look at Adolescent Girls and Boys." in Advertising to Children: Concepts and Controversies, eds. M. Carole Macklin and Les Carlson. Thousand Oaks: Sage Publications, 165-

Meyers-Levy, Joan. 1991. "Elaborating on Elaboration: The Distinction Between Relational and Item-Specific Elaboration." Journal of Consumer Research 18 (December): pp 358-367.

Meyers-Levy, Joan and Durairaj Maheswaran. 1991. "Exploring the Differences in Males' and Females' Processing Strategies." Journal of Consumer Research 18 (June): pp 63-70.

Meyers-Levy, Joan and Prashant Malaviya. 1999. "Consumers' Processing of Persuasive Advertisements: An Integrative Framework of Persuasion Theories." Journal of Marketing 63 (Special Issue): pp 45-60.

Meyers-Levy, Joan and Brian Sternthal. 1991. "Gender Differences in the Use of Message Cues and Judgments." Journal of Marketing Research 28 (February): pp 8496.

Meyers-Levy, Joan and Alice M. Tybout. 1989. "Schema Congruity as a Basis for Product Evaluation." Journal of Consumer Research 16 (June): pp 39-54.

Palan, Kay M. 2001. "Gender Identity in Consumer Behavior Research: A Literature.

Richins, Marsha L. 1991. "Social Comparison and the Idealized Images of Advertising." Journal of Consumer Research 18 (June): pp 71-83.

Risman, Barbara J. 1998. Gender Vertigo: American Families in Transition/. New Haven: Yale University Press.

Schmitt, Bernd H., France Leclerc and Laurette Dubé-Rioux. 1988. "Sex Typing and Consumer Behavior: A Test of Gender Schema Theory." Journal of Consumer Research 15 (June): pp 122-128. 
Sengupta, Jaideep, Ronald C. Goodstein and David S. Boninger. 1997. "All Cues are not Created Equal: Obtaining Attitude Persistence Under Low-Involvement Conditions." Journal of Consumer Research 23 (March): pp 351-361.

Shapiro, Stewart. 1999. "When an Ad's Influence is Beyond Our Conscious Control: Perceptual and Conceptual Fluency Effects Caused by Incidental Ad Exposure." Journal of Consumer Research 26 (June): pp 16-36.

Simon, Bernd, Claudia Hastedt and Birgit Aufderheide. 1997. "When SelfCategorization Makes Sense: The Role of Meaningful Social Categorization in Minority and Majority Members' Self-Perception.” Journal of Personality and Social Psychology 73 (2): pp 310-320.

Simon, Bernd, Giuseppe Pantaleo and Amélie Mummendey. 1995. "Unique Individual or Interchangeable Group Member? The Accentuation of Intragroup Differences Versus Similarities as an Indicator of the Individual Self Versus the Collective Self." Journal of Personality and Social Psychology 69 (1): pp 106-119.

Sirgy, M. Joseph. 1982. "Self-Concept in Consumer Behavior: A Critical Review." Journal of Consumer Research 9 (December): pp 287-300.

Smith, Eliot R., Russell H. Fazio and Mary Ann Cejka. 1996. "Accessible Attitudes Influence Categorization of Multiply Categorical Objects." Journal of Personality and Social Psychology 71 (5): pp 888-898.

Sujan, Mita. 1985. "Consumer Knowledge: Effects on Evaluation Strategies Mediating Consumer Judgments." Journal of Consumer Research 12 (June): pp 3146.

Tajfel, Henri. 1981. Human Groups and Social Categories: Studies in Social Psychology/. New York: Cambridge University Press.

Tajfel, Henri and John C. Turner. 1986. "The Social Identity Theory of Intergroup Behavior." in Psychology of Intergroup Relations, ed. Stephen Worchel and William G. Austin. Chicago, IL: Nelson-Hall Publishers, pp 7-24.

Terry, Deborah J. and Michael A. Hogg. 1996. "Group Norms and the AttitudeBehavior Relationship: A Role for Group Identification." Personality and Social Psychology Bulletin 22 (8): pp 776-793.

Turner, John C. 1982. "Towards a Cognitive Redefinition of the Social Group." in Social Identity and Intergroup Relations, ed. H. Tajfel. Cambridge, England: Cambridge University Press, pp 15-40. 
Turner, John C. 1987. Rediscovering the Social Group: A Self-Categorization Theory/. Oxford: Basil Blackwell.

Turner, John C., Penelope J. Oakes, S. Alexander Haslam and Craig McGarty. 1994. "Self and Collective: Cognition and Social Context." Personality and Social Psychology Bulletin 20 (5): pp 454-463.

West, Candice and Don H. Zimmerman. 1987. "Doing Gender." Gender \& Society 1 (2): pp 125-151.

Yi, Youjae. 1990. "The Effects of Contextual Priming in Print Advertisements." Journal of Consumer Research 17 (September)

Unless it is obvious that the individual concerned is peculiarly unable to grasp his own needs, and it is imagined that the community is better able to make his judgments for him than he is for himself, legislation of this kind would seem to be actually immoral. For to remove from the individual the right and the power to make his own choices, is to remove him from the class of moral agents and to treat him as a kind of mechanical device.

\section{Leslie Armour, "The Concept of Crime"} Philosophy in Context, Vol. 2, 1973, p. 39 
https://ir.iba.edu.pk/businessreview/vol3/iss2/10

DOI: https://doi.org/10.54784/1990-6587.1156

Business Review - Volume 3 Number 2

July-December 2008

The knowledge society will face two serious problems, one economic, one social.

The society in which knowledge workers dominate is in danger of a new "class conflict" between the large minority of knowledge workers and the majority of people who will make their living through traditional ways, either by manual work..... or by service work. The productivity of knowledge work - still abysmally low will predictably become the economic challenge of the knowledge society......The productivity of the non-knowledge service worker will increasingly become the social challenge of the knowledge society. On it will depend the ability of the knowledge society to give decent incomes, and with them dignity and status, to nonknowledge people.

That is the peril of the knowledge society; its promise is that it will be the "first society in which ordinary common people - and that means most people - do not earn their daily bread by the sweat of their brow. It is the first society in which 'honest work' does not mean a callused hand." This is far more than a social change. "It is a change in the human condition."

Jack Beatty

The World According to Drucker, p. 177-178 